\title{
Medical isotope shortage reaches crisis level
}

\section{Robust solutions sought urgently to shore up fragile supply chain.}

The worldwide shortage of medical isotopes is about to get much worse this week, as the High Flux Reactor in Petten, the Netherlands, closes for a month-long maintenance inspection.

It joins the National Research Universal reactor in Chalk River, Ontario, Canada, which has been closed since 15 May because of a heavywater leak and is unlikely to restart before late 2009, according to Atomic Energy of Canada Limited, the government-sponsored body that runs the facility.

Together, the reactors produce two-thirds of the global supply of molybdenum-99, which decays to form technetium-99m, an isotope that is used in about 70,000 medical imaging procedures worldwide every day.

The shutdown has prompted calls for a major review of the way that medical isotopes are made and distributed. All five commercial nuclear reactors that use neutron-induced fission of highly enriched uranium-235 to make ${ }^{99} \mathrm{Mo}$ (see map) are more than 40 years old and cracks are beginning to emerge. The Petten reactor is scheduled to close again in early 2010 for up to six months so that deformed pipes in its cooling system can be repaired.

With both reactors unavailable for significant periods, "you really do have to say: 'right, let's clear the table and start all over", says Thomas Ruth, senior research scientist at TRIUMF, Canada's national laboratory for particle and nuclear physics in Vancouver.

The problem arises because isotopes cannot be stockpiled $-{ }^{99}$ Mo has a half life of 66 hours and
${ }^{99 \mathrm{~m}} \mathrm{Tc}$ of just six hours. ${ }^{99}$ Mo created in nuclear reactors must be shipped quickly to facilities that process the material into ${ }^{99 \mathrm{~m}} \mathrm{Tc}$ generators. These generators are delivered to hospitals on a weekly basis, where they are 'milked' every morning to deliver ${ }^{99 m} \mathrm{Tc}$. Although the reactors in Belgium and South Africa will be working at full power over the next few weeks to produce more ${ }^{99}$ Mo than usual, isotope suppliers say they will probably not be able to meet the shortfall. The shortage has been particularly acute in the United States and Canada, and "the situation will get much worse”, says Michael Graham, director of nuclear medicine at the University of Iowa in Iowa City, and president of the international Society of Nuclear Medicine based in Reston, Virginia. "It is likely many studies will be cancelled or postponed."

\section{Leaky pipeline}

Week-by-week availability of ${ }^{99}$ Mo is now coordinated by the Brussels-based Association of Imaging Producers and Equipment Suppliers (AIPES), which in the past year has taken the initiative to stimulate global action on the isotope crisis. Both the AIPES and the Organisation for Economic Co-operation and Development (OECD), based in Paris, began to investigate long-term solutions to the chronic shortage of ${ }^{99} \mathrm{Mo}$ at the start of 2009 . But given the importance of ${ }^{99 \mathrm{~m}} \mathrm{Tc}$ in health care, the ageing reactor infrastructure and highly fragmented supply network needs a root-and-branch overhaul.

"We must upgrade and invest in updates to

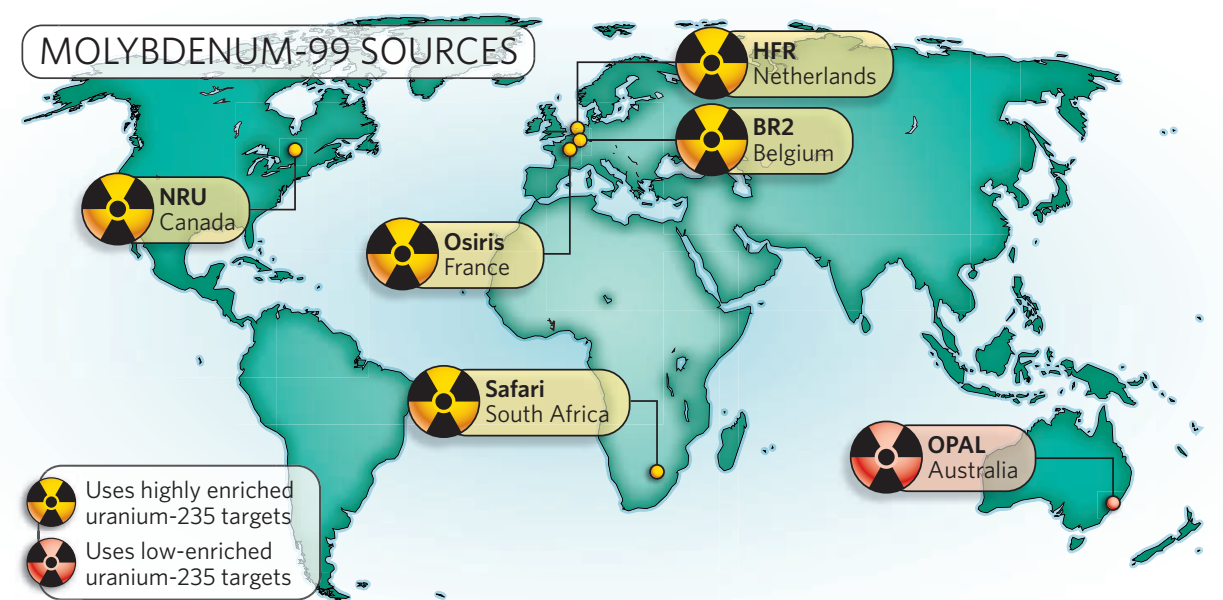

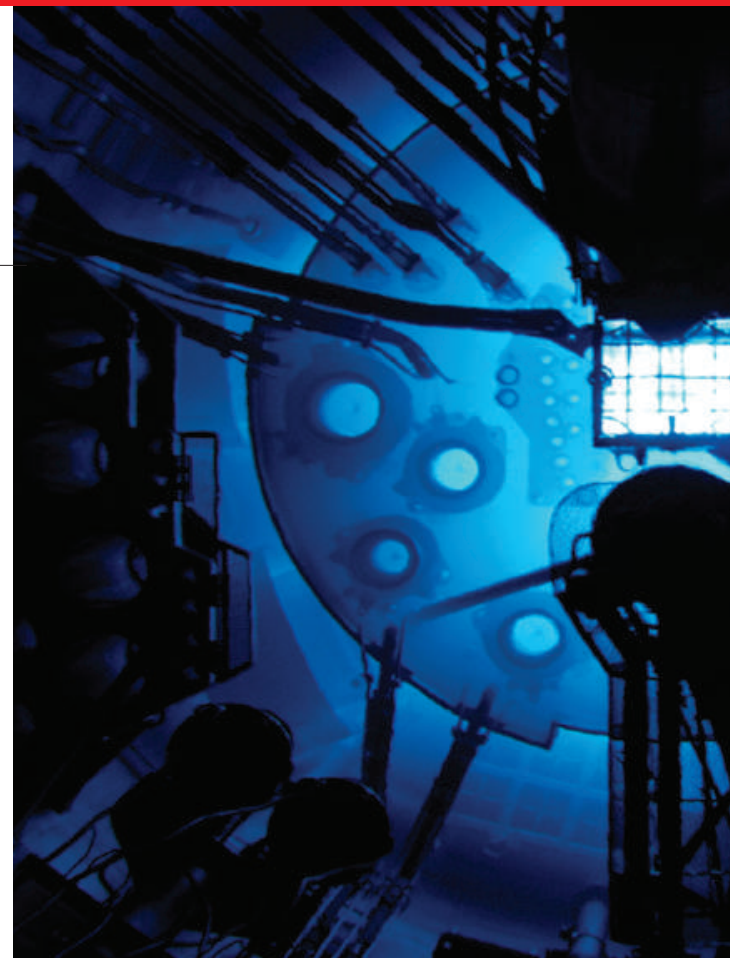

these ageing reactors," says George Segall, chief of the nuclear-medicine service at the Veterans' Affairs Palo Alto Health Care System in California. "Many of these reactors have already exceeded their useful lifetime. No one expected that they would still be needed now when they were built."

The Canadian government has so far resisted calls to switch on two Multipurpose Applied Physics Lattice Experiment (MAPLE) reactors, built at the Chalk River site to replace the 52-year-old National Research Universal reactor. The MAPLE reactors were to be the first nuclear reactors in the world dedicated to production of medical isotopes, but are lying dormant after Atomic Energy of Canada Limited halted development in May 2008, citing safety issues that it claimed it would be too expensive to resolve. If started up, these reactors alone could deliver more than the current global requirement for medical isotopes, according to Harold Smith, who was a manager on the MAPLE project.

Some medical-isotope suppliers are looking to academic research reactors to fill the gap. MDS Nordion, a medical-isotope provider based in Ottawa, Canada, that had invested heavily in the ill-fated MAPLE project, is negotiating with the Karpov Institute of Physical Chemistry in Moscow, which holds a 90\% share of the market for ${ }^{99 \mathrm{~m}} \mathrm{Tc}$ generators in Russia.

Researchers at Germany's Technical University of Munich are seeking financial backing from the government to support an upgrade to the university's FRM II neutron source to create ${ }^{99} \mathrm{Mo}$. If highly enriched ${ }^{235} \mathrm{U}$ targets were used, the reactor could satisfy almost all of Europe's needs for ${ }^{99 \mathrm{~m}} \mathrm{Tc}$ once it becomes fully operational, says Winfried Petry, scientific director of the FRM II.

An alternative option, says Ruth, could be to fire high-energy electrons at ${ }^{100}$ Mo targets, forcing out a neutron to create ${ }^{99} \mathrm{Mo}$. This 
